\title{
REVIEW
}

Open Access

\section{Comparison of the overall survival of proximal and distal gastric cancer after gastrectomy: a systematic review and meta-analysis}

Jiaming Xue ${ }^{1,2 \dagger}$, Huiliang Yang ${ }^{1,2 \dagger}$, Shanshan Huang ${ }^{2,3 \dagger}$, Tingting Zhou ${ }^{3}$, Xiangwen Zhang ${ }^{1 *}$ and Guo Zu ${ }^{1 *}$ (D)

\begin{abstract}
Background: The aim of this study was to investigate the overall survival (OS) between proximal gastric cancer $(\mathrm{PG})$ and distal gastric cancer (DG) patients after gastrectomy.

Methods: Articles on the prognostic study of PG and DG patients after gastrectomy were collected from the PubMed, EMBASE, Web of Science, Cochrane Library, China National Knowledge Infrastructure (CNKI), Wanfang, and VIP databases from the date of establishment until December 2020. The data were statistically analyzed by Stata software (version 11.0, StataCorp).

Results: A total of 10 articles met the inclusion criteria. Meta-analysis showed that the 1-, 3- and 5-year OS rates of $P G$ patients were significantly lower than those of DG patients ( $R R=0.898,95 \% \mathrm{Cl}: 0.825$ to $0.977, P=0.013$; $R R=$ $0.802,95 \% \mathrm{Cl}: 0.708$ to $0.909, P=0.001 ; \mathrm{RR}=0.736,95 \% \mathrm{Cl}: 0.642$ to $0.844, P=0.000$ ). After subgroup analysis according to different countries, the combined RR values of were as follows: 1-year OS: eastern countries: RR $=$ $0.966,95 \%$ Cl: 0.944 to $0.988, P=0.003$, western countries: $R R=0.687,95 \% \mathrm{Cl}: 0.622$ to $0.759, P=0.000$; 3-year OS: eastern countries: $\mathrm{RR}=0.846,95 \% \mathrm{Cl}: 0.771$ to $0.929, P=0.000$, western countries: $\mathrm{RR}=0.742,95 \% \mathrm{Cl}: 0.399$ to 1.382, $P=0.348$; and 5-year OS: eastern countries: $\mathrm{RR}=0.798,95 \% \mathrm{Cl}: 0.716$ to $0.889, P=0.000$, western countries: $\mathrm{RR}=0.646,95 \% \mathrm{Cl}: 0.414$ to $1.008, P=0.054$.

Conclusion: In terms of 1-, 3-, and 5-year OS, PG patients had lower rates than DG patients and the eastern countries/western countries subgroup, but there were no significant differences in 3- and 5-year OS for the western countries. These results merit further clinical validation in future studies.

(Registration ID: UMIN000040393; Date of registration: 2020/05/13)
\end{abstract}

Keywords: Gastric cancer, Proximal gastric cancer, Distal gastric cancer, Prognosis, Meta-analysis

\footnotetext{
*Correspondence: dr-zhang@hotmail.com; zushanghai@163.com

${ }^{\dagger}$ Jiaming Xue, Huiliang Yang and Shanshan Huang contributed equally to this work.

'Department of Gastroenterology Surgery, The Dalian Municipal Central Hospital Affiliated of Dalian Medical University, No. 826 Southwest Road Shahekou District, Dalian 116033, P.R. China

Full list of author information is available at the end of the article
}

C C The Author(s). 2021 Open Access This article is licensed under a Creative Commons Attribution 4.0 International License, which permits use, sharing, adaptation, distribution and reproduction in any medium or format, as long as you give appropriate credit to the original author(s) and the source, provide a link to the Creative Commons licence, and indicate if changes were made. The images or other third party material in this article are included in the article's Creative Commons licence, unless indicated otherwise in a credit line to the material. If material is not included in the article's Creative Commons licence and your intended use is not permitted by statutory regulation or exceeds the permitted use, you will need to obtain permission directly from the copyright holder. To view a copy of this licence, visit http://creativecommons.org/licenses/by/4.0/. The Creative Commons Public Domain Dedication waiver (http://creativecommons.org/publicdomain/zero/1.0/) applies to the data made available in this article, unless otherwise stated in a credit line to the data. 


\section{Introduction}

Gastric cancer (GC) is one of the most common cancers of the digestive system [1]. A total of 1,000,000 new GC cases and 783,000 GC-related deaths occurred worldwide in 2018 [2]. Among them, the incidence rates in East Asian countries such as Korea, Japan, Mongolia, and China are the highest [3], affecting between 40 and 60 per 100,000 inhabitants [4]. This difference may be caused by Helicobacter pylori infection, poor diet, and unhealthy habits, such as smoking or alcohol consumption [5].

Common types of GC include proximal (PG) and distal GC (DG). PG is defined as cancers with the center located in the cardia or fundus, whereas DG is defined as lesions in the body, antrum, or pylorus [6]. Some early GC patients cannot be easily diagnosed because the early symptoms are not obvious or for other reasons. At this time, surgery is still an important method to improve their survival rate of GC patients [7]. Depending on the location of the tumor, different surgical methods are usually selected, such as proximal gastrectomy or distal gastrectomy. There have been many reports about PG and DG, but their findings are quite different. For instance, Choi et al. and Fatih et al. reported that DG patients had higher 5-year overall survival (OS) rates than PG patients $[8-10]$. This may be related to the more insidious early symptoms in PG patients, and many PG patients are already at an advanced stage when they diagnosed, which leads to worse prognosis. However, Qin et al. and Laurence et al. reported no difference in OS between DG and PG [11, 12]. The different prognosis of DG and PG patients are of great significance in guiding surgical treatment. Therefore, to explore the differences in prognosis between PG and DG patients, we extracted and integrated the 1-, 3-, and 5-year OS rates from articles and performed a systematic review and meta-analysis, with the aim of providing evidence for the prognostic evaluation of GC after gastrectomy.

\section{Methods}

This study is reported in line with the Preferred Reporting Items for Systematic Reviews and Meta-Analyses (PRIS MA) [13] and Assessing the Methodological Quality of Systematic Reviews (AMSTAR) guidelines [14].

\section{Data sources and searches}

We systematically searched the PubMed, EMBASE, Web of Science, Cochrane Library, China National Knowledge Infrastructure (CNKI), Wanfang, and VIP databases from the date of establishment until December 2020. The search terms were follows: "proximal gastric cancer" and "distal gastric cancer" and ("prognosis" or "overall survival” or OS) and (gastrectomy or surgery). In addition, we reviewed the references of all selected articles to identify other relevant studies.

\section{Inclusion and exclusion criteria}

The inclusion criteria were as follows: (1) randomized controlled trials (RCTs)/cohort studies/observational studies, (2) comparison of prognosis between PG and DG patients, and (3) recorded at least one of the following effect sizes: 1-, 3-, or 5-year OS.

The exclusion criteria were as follows: (1) nongastric cancer; (2) failed to include both PG and DG patients; (3) too little data to use; (4) case reports, reviews, and comments; and (5) not following gastrectomy.

\section{Data extraction and quality assessment}

Two reviewers independently searched all the preliminary inclusion reports for information extraction and evaluation. The extracted information included the following: first author, country, publication year, number of patients, and 1-, 3-, and 5-year OS. The NewcastleOttawa Scale (NOS) was used to evaluate the quality of the included articles. The evaluation contents were "selection," "comparability" and "exposure/outcome", and every high-quality component given a "star". The differences were settled by discussion with all the authors together.

\section{Statistical analysis}

All data were analyzed with Stata software (version 11.0, StataCorp). The relative risk (RR) with a $95 \%$ confidence interval $(\mathrm{CI})$ was used to analyze the survival rate. Heterogeneity was evaluated by the $\mathrm{Q}$ value and $I^{2}$ test. The corresponding combination method according to the

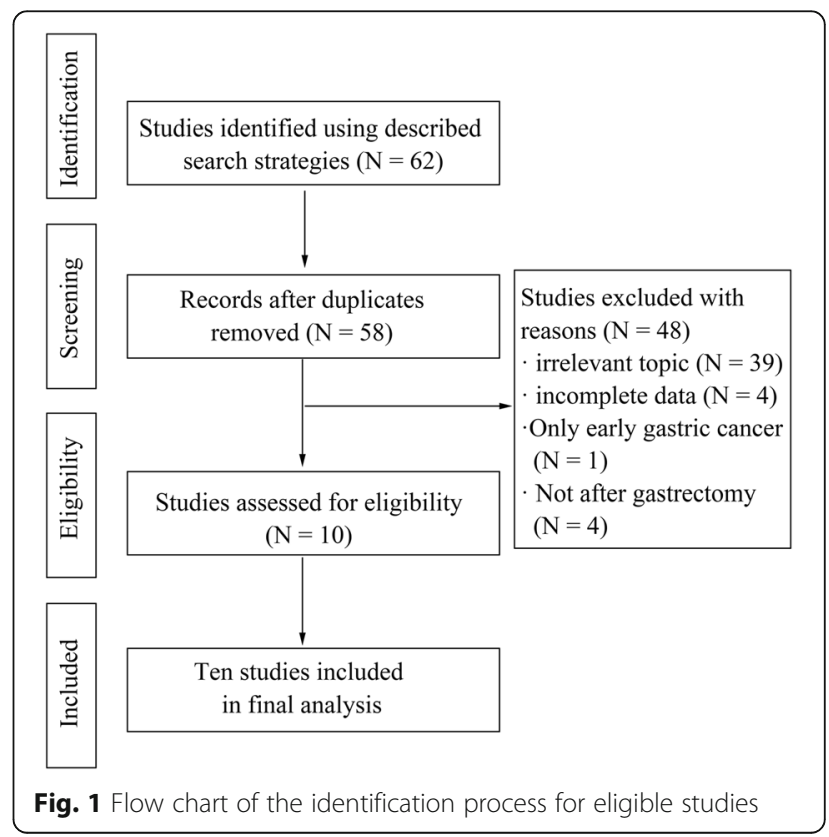




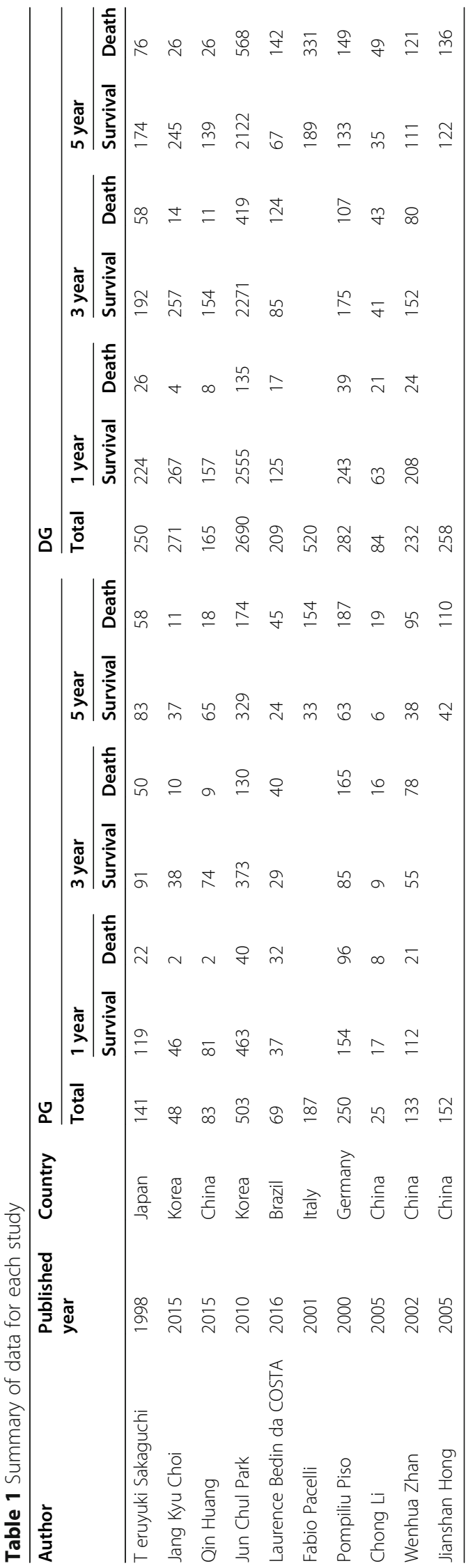


results of the heterogeneity test: if there was no significant heterogeneity among groups $(P \geq 0.1)$, the fixed effect model was selected for combination and analysis; if there was significant heterogeneity among groups $(P<$ 0.1 , the random effect model was selected for combination and analysis. The source of heterogeneity among studies was explored by subgroup and sensitivity analyses. Finally, publication bias was assessed by Begg's test and Egger's test. A level of $\alpha=0.05$ was considered significant.

\section{Results}

\section{Eligible studies}

We initially retrieved 62 articles, and then excluded 4 duplicate articles. By reading the titles and abstracts, 39 irrelevant topic articles were excluded. Then, by reading the full texts of the remaining articles, according to the inclusion and exclusion criteria, we excluded 4 articles with incomplete data, 1 article with only early cases, and 4 articles without gastrectomy. Finally, we included 10 studies, with 3 in Chinese and 7 in English [8, 10-12, 15-20]. Figure 1 shows the flow chart of the selection process. Table 1 records the data from each study. We evaluated the studies by NOS, and the NOS score obtained a range of 5-6 stars, indicating that the quality of the included studies was at a medium to high level (Table 2).

\section{Outcomes of the meta-analysis}

The 1-year OS was described in 8 studies $[8,11,12$, 15-19]. The results suggested that there was significant heterogeneity $\left(Q=77.61, I^{2}=91.0 \%, P=0.000\right)$ among the groups in the fixed effect model. Therefore, we used the random effect model to analyze the data. The results were $\mathrm{RR}=0.898,95 \% \mathrm{CI}: 0.825$ to 0.977 . The test result was statistically significant $(P=0.013)$ (Table 3 and Fig. 2a) and suggested a difference in the 1-year OS between PG and DG patients, namely, the 1-year survival rate of PG patients was lower than that of DG patients.

Table 2 NOS score sheet

\begin{tabular}{|c|c|c|c|}
\hline & Selection & Comparability & Outcome \\
\hline T eruyuki Sakaguchi 1998 & $\star \star \star \star 々$ & 象动 & $\star \star \lesssim$ \\
\hline Jang Kyu Choi 2015 & $\star \star \star \star ぇ$ & 论坋 & $\star \star \Sigma \tau$ \\
\hline Qin Huang 2015 & $\star \star \star \star 々$ & 象动 & $\star \star \star$ \\
\hline Jun Chul Park 2010 & $\star \star \star \star 々 \zeta$ & 象论 & 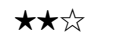 \\
\hline Laurence Bedin da COSTA 2016 & $\star \star \star \star 々$ & 象约 & $\star \star \star$ \\
\hline Fabio Pacelli 2001 & 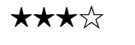 & 论弥 & $\star \star \Sigma$ \\
\hline Pompiliu Piso 2000 & $\star \star \star \star \hat{\jmath}$ & $\hat{2}$ & $\star \star \star \hat{\zeta}$ \\
\hline Chong Li 2005 & $\star \star \star \star 々$ & $\star \Sigma$ & $\star \star \star \tau$ \\
\hline Wenhua Zhan 2002 & $\star \star \star \star 々$ & $\sum \hat{s}$ & $\star \star \star$ \\
\hline Jianshan Hong 2005 & $\star \star \star \star 々 / 2$ & 论坛 & $\star \star \lesssim$ \\
\hline
\end{tabular}

The 3-year OS was also described in 8 studies $[8,11$, $12,15-19]$. The results of the random effect model analysis showed that $\mathrm{RR}=0.802,95 \% \mathrm{CI}: 0.708$ to 0.909 , and the results were statistically significant $(P=0.001)$ (Table 3 and Fig. 2b). These findings suggested that the 3-year survival rate of PG patients was lower than that of DG patients.

The 5-year survival rate was described in 10 studies [8, $10-12,15-20]$. The results of the random effect model analysis showed that $\mathrm{RR}=0.736,95 \% \mathrm{CI}: 0.642$ to 0.844 , $P=0.000$ (Table 3 and Fig. 2c). Thus, PG patients had a worse prognosis in terms of the 5-year OS.

\section{Subgroup analysis}

The 1-year OS was described in 8 studies. Due to the high degree of heterogeneity, we conducted subgroup analysis to explore possible sources. We divided the studies into two subgroups according to their countries: group 1 (eastern countries) and group 2 (western countries). Figure 3a shows the results of the subgroup analysis of 1-year OS. The heterogeneity testing in each subgroup revealed that there was no heterogeneity among the studies (1. $Q=7.02, I^{2}=28.8 \%, P=0.219 ; 2$. $\left.Q=1.59, I^{2}=37 \%, P=0.208\right)$. Therefore, we used a fixed effect model to merge RR $(1 . \mathrm{RR}=0.966,95 \% \mathrm{CI}$ : 0.944 to $0.988, P=0.003 ; 2$. RR $=0.687,95 \% \mathrm{CI}: 0.622$ to $0.759, P=0.000$ ), which suggested that the 1 -year OS of PG patients was lower than that of DG patients.

In terms of the 3-year OS, the results of subgroup analysis suggested that there was still heterogeneity among the studies $\left(1 . Q=15.44, I^{2}=67.6 \%, P=0.009 ; 2 . Q=\right.$ $\left.10.91, I^{2}=90.8 \%, P=0.001\right)$. The RR values combined with the random effect model were (1) $\mathrm{RR}=0.846,95 \%$ CI: 0.771 to $0.929, P=0.000$, and (2) $\mathrm{RR}=0.742,95 \%$ CI: 0.399 to $1.382, P=0.348$ (Fig. $3 \mathrm{~b}$ ). Thus, the 3 -year OS of PG patients was lower than that of DG patients in eastern countries, but there was no statistical significance in western countries.

When analyzing the 5-year OS of patients, the results of subgroup analysis suggested that there was still heterogeneity among the studies $\left(1 . Q=16.02, I^{2}=62.5 \%\right.$, $\left.P=0.014 ; 2 . Q=11.95, I^{2}=83.3 \%, P=0.003\right)$. The combined $R R$ values were (1) $R R=0.798,95 \% \mathrm{CI}: 0.716$ to $0.889, P=0.000$, and (2) $\mathrm{RR}=0.646,95 \% \mathrm{CI}: 0.414$ to 1.008, $P=0.054$ (Fig. 3c). Thus, the 5-year OS of PG patients was lower than that of DG patients in eastern countries, but there was no statistical significance in western countries.

\section{Publication bias}

Publication bias was analyzed by Begg's test and Egger's test in our study. The results of Begg's test and Egger's test of 1-year OS (Begg's test: $z=1.86, P=0.063$; Egger's test: $P=0.106$ ), 3-year OS (Begg's test: $z=1.11, P=0.266$; 
Table 3 RR value of OS obtained by random model

\begin{tabular}{|c|c|c|c|c|c|c|}
\hline \multirow[t]{2}{*}{ Study (year) } & \multicolumn{2}{|l|}{1 year } & \multicolumn{2}{|l|}{3 year } & \multicolumn{2}{|l|}{5 year } \\
\hline & $\mathrm{RR}(95 \% \mathrm{Cl})$ & Weight (\%) & RR $(95 \% \mathrm{Cl})$ & Weight (\%) & RR (95\% Cl) & Weight (\%) \\
\hline T eruyuki Sakaguchi (1998) & $0.942(0.867-1.023)$ & 14.05 & $0.840(0.731-0.967)$ & 14.83 & $0.846(0.720-0.993)$ & 12.70 \\
\hline Jang Kyu Choi (2015) & $0.973(0.915-1.034)$ & 14.96 & $0.835(0.720-0.968)$ & 14.52 & $0.853(0.727-1.000)$ & 12.73 \\
\hline Qin Huang (2015) & $1.026(0.977-1.076)$ & 15.39 & $0.955(0.877-1.040)$ & 16.81 & $0.930(0.815-1.060)$ & 13.48 \\
\hline Jun Chul Park (2010) & $0.969(0.943-0.996)$ & 15.93 & $0.878(0.832-0.927)$ & 17.64 & $0.829(0.776-0.886)$ & 14.83 \\
\hline Laurence Bedin (2016) & $0.609(0.485-0.765)$ & 7.49 & $1.033(0.749-1.426)$ & 8.24 & $1.085(0.743-1.584)$ & 7.07 \\
\hline Pompiliu Piso (2000) & $0.715(0.641-0.797)$ & 12.81 & $0.548(0.451-0.666)$ & 12.60 & $0.534(0.417-0.684)$ & 10.26 \\
\hline Chong Li (2005) & $0.907(0.674-1.219)$ & 5.47 & $0.738(0.418-1.300)$ & 3.83 & $0.576(0.274-1.210)$ & 2.79 \\
\hline Wenhua Zhan (2002) & $0.939(0.862-1.023)$ & 13.91 & $0.631(0.505-0.789)$ & 11.53 & $0.597(0.442-0.806)$ & 8.84 \\
\hline Fabio Pacelli (2001) & - & - & - & - & $0.486(0.349-0.675)$ & 8.13 \\
\hline Jianshan Hong (2005) & - & - & - & - & $0.584(0.438-0.779)$ & 9.16 \\
\hline Overall & $0.898(0.825-0.977)$ & 100.00 & $0.802(0.708-0.909)$ & 100.00 & $0.736(0.642-0.844)$ & 100.00 \\
\hline
\end{tabular}

Heterogeneity: 1-year survival: $Q=77.61, I^{2}=91.0 \%, P=0.000$. 3-year survival: $Q=42.13, I^{2}=83.4 \%, P=0.000 .5$-year survival: $Q=43.41, P^{2}=79.3 \%, P=0.000 . z$ test: 1 -year survival: $z=2.49, P=0.013$. 3-year survival: $z=3.46, P=0.001$. 5 -year survival: $z=4.39, P=0.000$

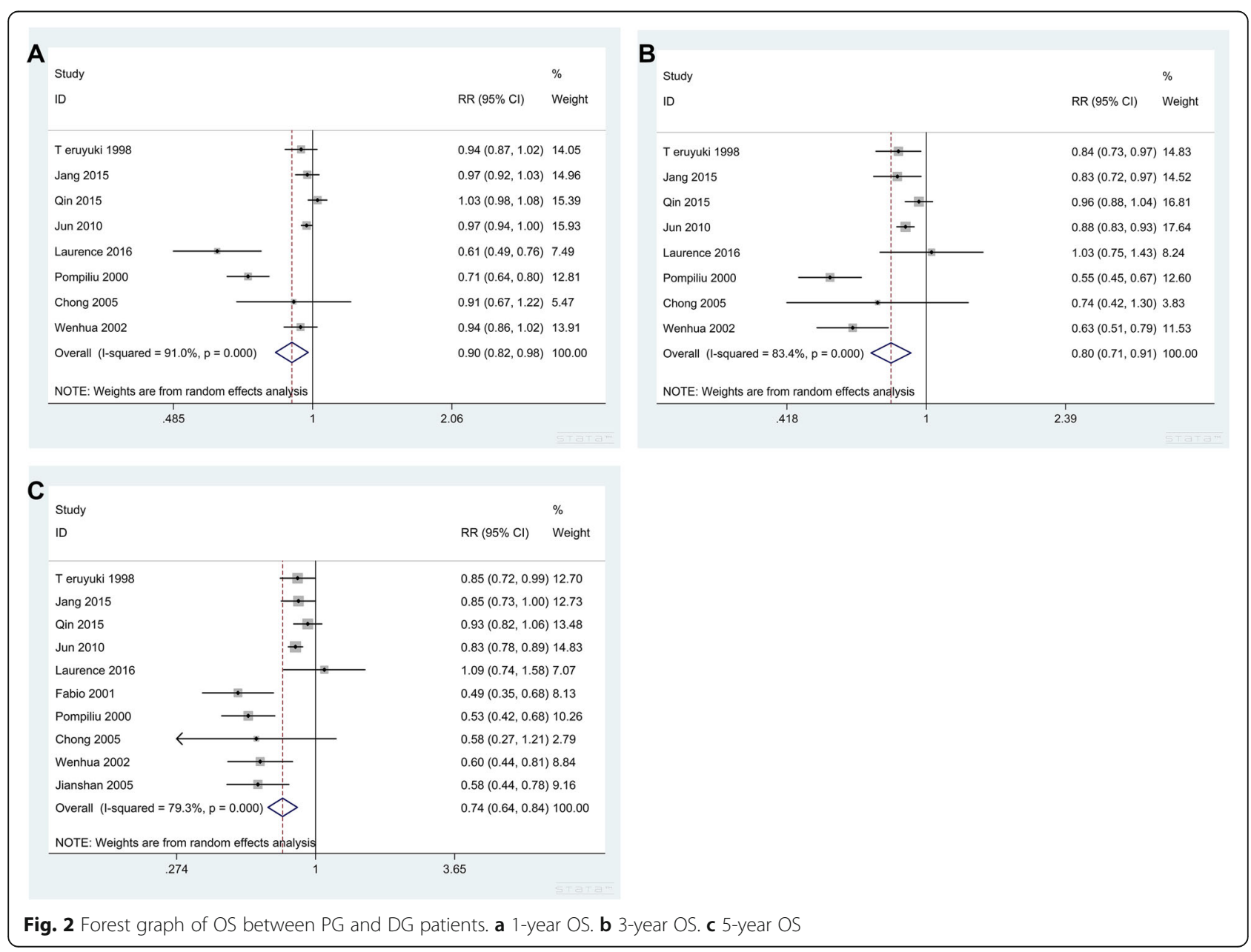




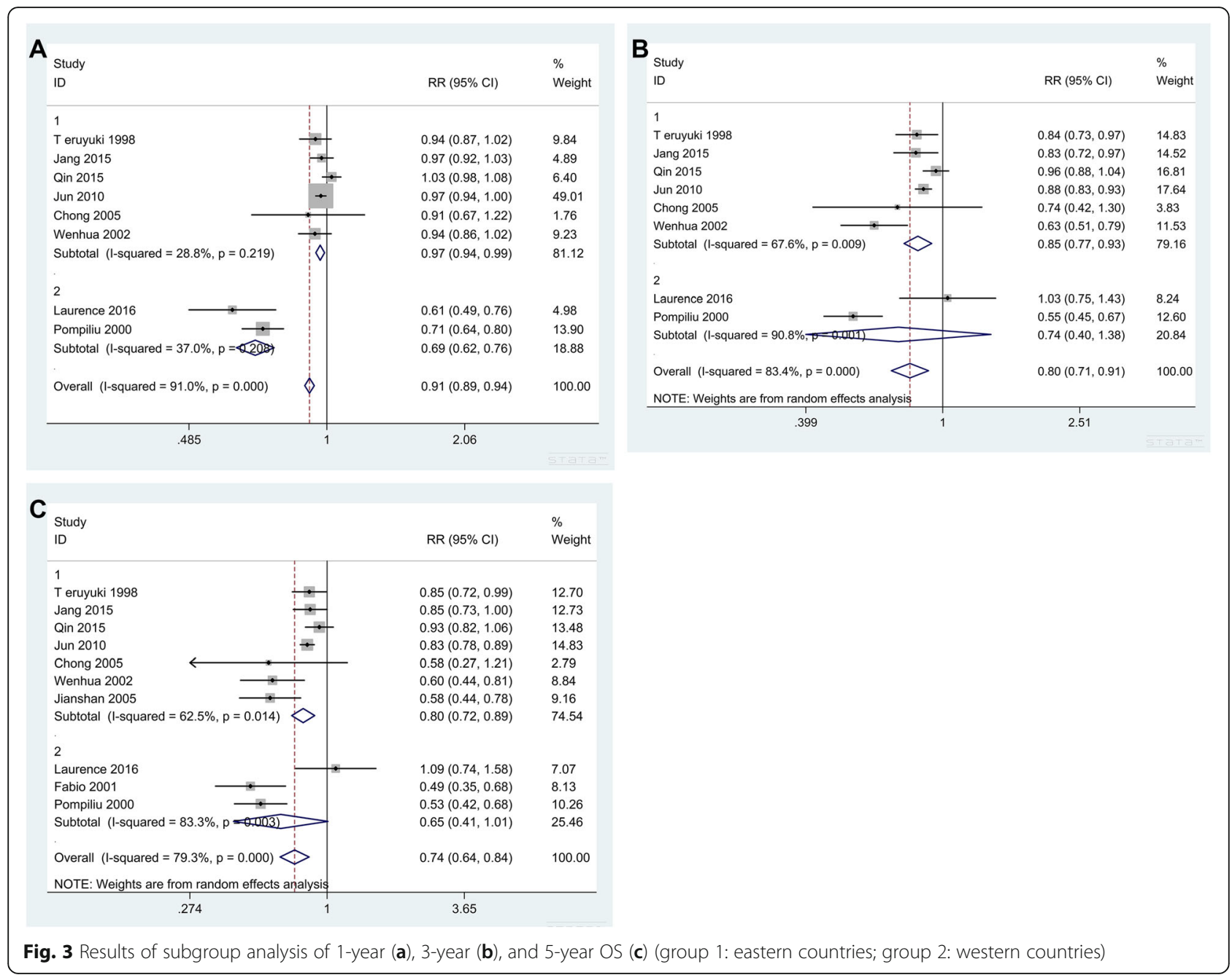

Egger's test: $P=0.231$ ), and 5-year OS (Begg's test: $z=$ 1.07, $P=0.283$; Egger's test: $P=0.133$ ) suggested that there was no significant publication bias (Fig. 4).

\section{Sensitivity analysis}

To explore the potential heterogeneity from any single included study, we carried out a sensitivity analysis, and the results are shown in Fig. 5. This sensitivity analysis indicated that the conclusions were not significantly affected by removing any single study.

\section{Discussion}

$\mathrm{GC}$ is one of the most important cancers worldwide. It became the fifth most frequently diagnosed cancer and the third leading cause of cancer death worldwide in 2018 [2]. Although the incidence rate of GC has been reported to decline in some areas in recent years, GC is still one of the

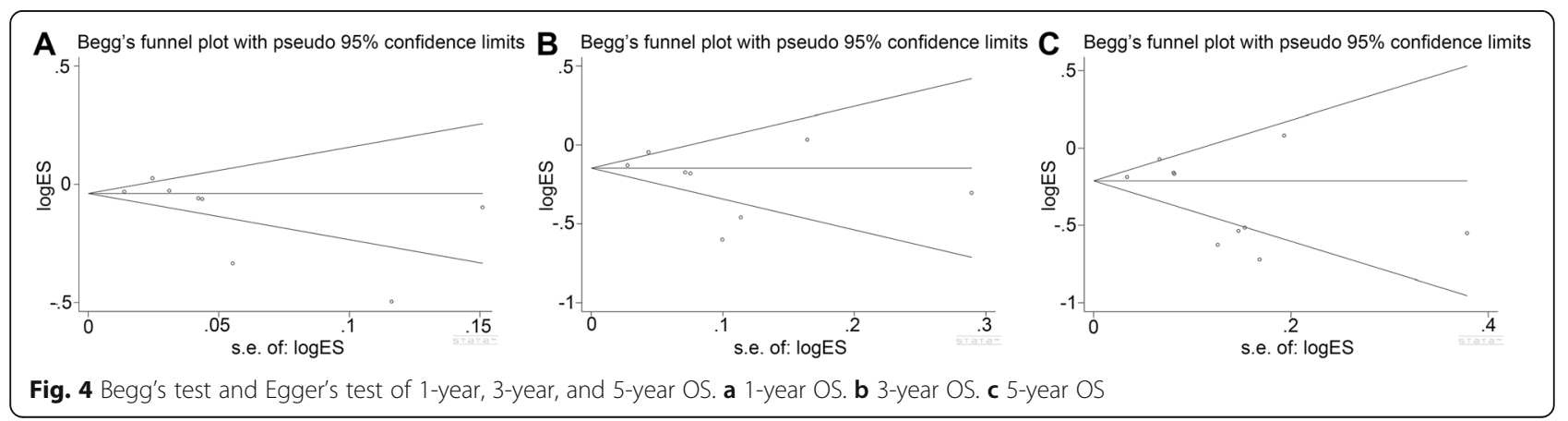




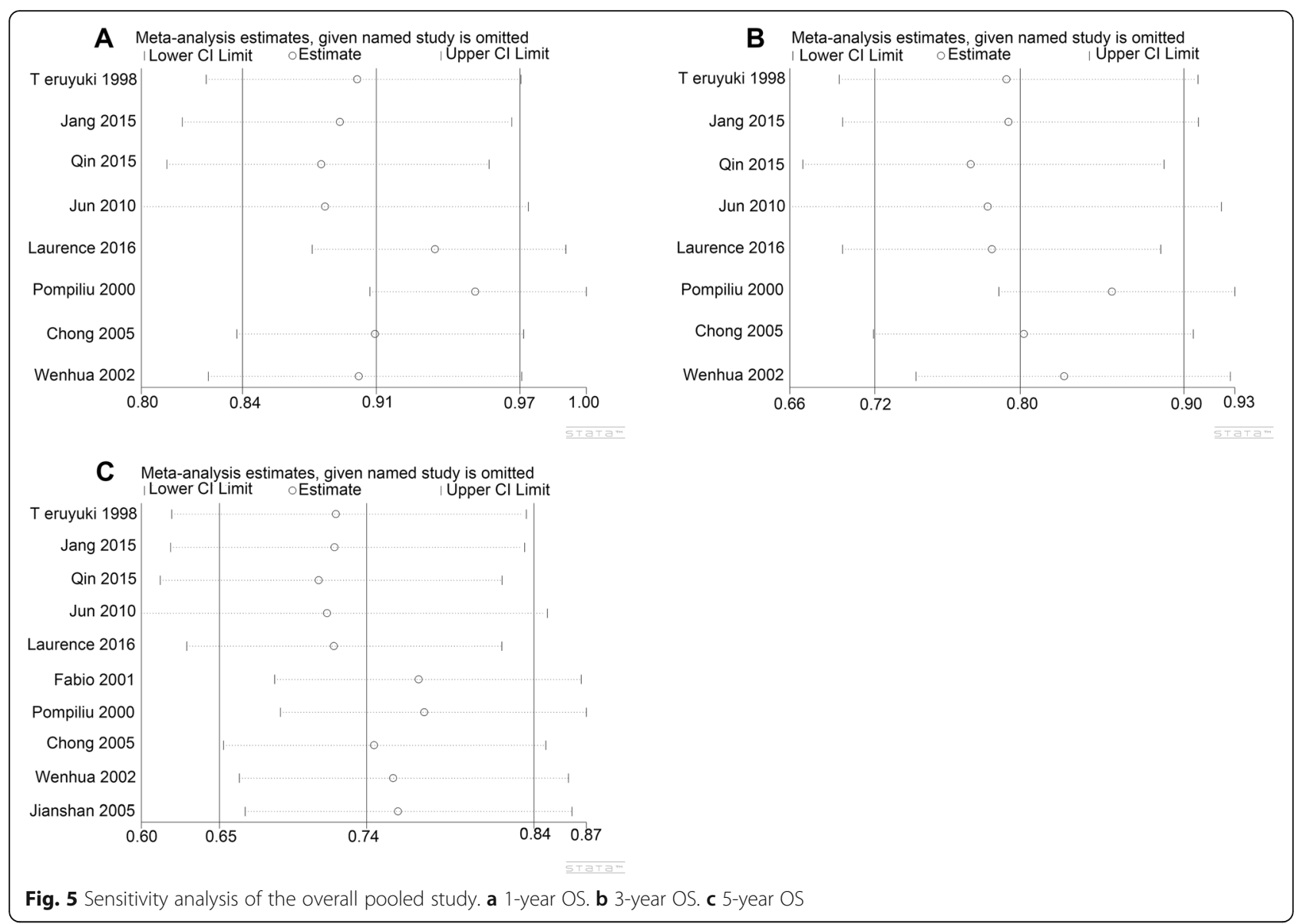

risk factors affecting global health, and the pathogenesis of $\mathrm{GC}$ is multifactorial $[4,21,22]$. With the rapid development of diagnosis and treatment of GC, surgery is still the major treatment for GC patients. PG and DG are the most common types of GC. Despite a decline in incidence of GC in western countries over the past decades, the incidence of PG is still increasing [23, 24]. This may be related to many factors such as Helicobacter pylori infection and eating habits [5, 25-28]. Many studies have reported the prognosis of PG and DG. It is expected that the prognosis of PG and DG will gradually increase with the increased availability of patient diagnostic facilities, improved effectiveness of multimodal treatment, promotion of cancer screening and early detection programs, and emerging surgical approaches. However, the results remain controversial. In our study, after meta-analysis and subgroup analysis, we found that the 1-year OS of PG patients was lower than that of DG patients, and the 3- and 5-year OS rates of PG patients were lower than those of DG patients in eastern countries, but there were no significant differences in western countries.

The reasons why PG patients have worse OS than DG patients have been investigated and are multifaceted. First, many PG patients do not have obvious or specific early symptoms, and detection is sometimes difficult with gastroscopy; even targeted biopsy may be less accurate, resulting in some patients not being diagnosed until the advanced stage of cancer [12]. PG patients with esophageal invasion (especially stage T2) have been reported to have a poor prognosis, which may be associated with a higher incidence of lymph node invasion, leading to a wider spread of the tumor [15, 29]. Similarly, Qin et al. suggested that patients with PG had more aggressive tumors, leading to poorer prognosis [17, 30, 31]. Furthermore, p53 gene mutation has been reported to be an independent prognostic factor for GC, and the survival rate of patients with p53positive tumors is often lower than that of patients with p53-negative tumors. They detected p53 more frequently in PG patients, which may explain the poor prognosis of PG patients compared to DG patients [15, 32, 33]. In addition, due to their different anatomical locations, the complexity of surgery in PG patients is significantly greater than that in DG patients, which may also be one of the factors contributing to the difference in prognosis [5]. In summary, these factors may ultimately lead to worse prognosis in PG patients than in DG patients.

Moreover, it is meaningful to further identify the reason for the difference in OS between PG and DG to develop better early screening, diagnosis, and treatment strategies 
for GC patients. At the same time, comparing the differences in screening, diagnosis, treatment strategies, and surgical methods in GC between eastern and western countries may provide suggestions for improving the OS of PG in eastern countries. Our results suggest that there is no significant difference in the 3- and 5-year OS rates between PG and DG patients in western countries. This may be related to the differences in the diagnosis and treatment of GC between the East and the West, such as earlier general survey, the basis of pathological diagnosis, the operation mode, and the adjuvant treatment plan [34, 35], but further clinical validation in future studies will be needed to confirm these possibilities.

Although our study used strict inclusion and exclusion criteria for article screening, there are still limitations. First, the impact of different surgical methods and adjuvant treatment schemes on the OS of patients with PG and DG patients was not considered. Second, we did not find the source of heterogeneity through sensitivity analysis and subgroup analysis, but we could confirm that regional factors were not the source of heterogeneity in this result. Perhaps the heterogeneity was related to other causes such as sex, but we do not have enough data to validate these conjectures. Furthermore, publication bias was not obvious in our results.

\section{Conclusion}

In conclusion, our meta-analysis showed that the 1-year OS rate of PG patients was lower than that of DG patients. However, the 3- and 5-year OS rates were different between eastern and western countries: the rates were lower in PG patients than in DG patients in eastern countries, but there was no significant difference in western countries. This result can provide evidence for the prognostic evaluation of GC after gastrectomy.

\section{Abbreviations}

OS: Overall survivalPGProximal gastric cancerDGDistal gastric cancerGCGastric cancerNOSNewcastle-Ottawa ScaleRRRelative risk; Cl: Confidence interval I ${ }^{2}$ I square statistic

\section{Acknowledgements}

Not applicable.

\section{Authors' contributions}

GZ and XZ designed the research. JX, HY, SH, and TZ collected and analyzed the data. JX wrote the manuscript. GZ, XZ, and JX are the guarantors of the paper. The authors read and approved the final manuscript.

\section{Funding}

This research did not receive any specific grant from funding agencies in the public, commercial, or not-for-profit sectors.

\section{Availability of data and materials}

All studies were retrieved from PubMed, EMBASE, Web of Science, Cochrane Library, China National Knowledge Infrastructure (CNKI), Wanfang, and VIP databases.

\section{Ethics approval and consent to participate}

This article is a meta-analysis, which does not contain any studies with human participants or animals performed by any of the authors, so without ethical approval process.

\section{Consent for publication}

Not applicable.

\section{Competing interests}

The authors declare that they have competing interests.

\section{Author details}

'Department of Gastroenterology Surgery, The Dalian Municipal Central Hospital Affiliated of Dalian Medical University, No. 826 Southwest Road Shahekou District, Dalian 116033, P.R. China. ${ }^{2}$ Dalian Medical University, Dalian 116011, P.R. China. ${ }^{3}$ Department of Neurology, The First Affiliated Hospital of Dalian Medical University, Dalian 116011, P.R. China.

Received: 29 July 2020 Accepted: 11 January 2021

Published online: 19 January 2021

\section{References}

1. Song Z, Wu Y, Yang J, Yang D, Fang X. Progress in the treatment of advanced gastric cancer. Tumour Biol. 2017;39(7):1010428317714626. https://doi.org/10.1177/1010428317714626.

2. Bray F, Ferlay J, Soerjomataram I, Siegel RL, Torre LA, Jemal A. Global cancer statistics 2018: GLOBOCAN estimates of incidence and mortality worldwide for 36 cancers in 185 countries. CA Cancer J Clin. 2018;68(6):394-424. https://doi.org/10.3322/caac.21492.

3. Torre LA, Bray F, Siegel RL, Ferlay J, Lortet-Tieulent J, Jemal A. Global cancer statistics, 2012. CA Cancer J Clin. 2015;65(2):87-108. https://doi.org/10.3322/caac.21262.

4. Correa P. Gastric cancer: overview. Gastroenterol Clin North Am. 2013;42(2): 211-7. https://doi.org/10.1016/j.gtc.2013.01.002.

5. Yu X, Hu F, Li C, Yao Q, Zhang H, Xue Y. Clinicopathologic characteristics and prognosis of proximal and distal gastric cancer. Onco Targets Ther. 2018;11:1037-44. https://doi.org/10.2147/OTT.S157378.

6. Wang $X$, Liu F, Li Y, Tang S, Zhang Y, Chen Y, et al. Comparison on clinicopathological features, treatments and prognosis between proximal gastric cancer and distal gastric cancer: a national cancer data base analysis. J Cancer. 2019;10(14):3145-53. https://doi.org/10.7150/jca.30371.

7. Wei B, Wei H. Surgical treatment strategy for advanced gastric cancer. Zhonghua Wei Chang Wai Ke Za Zhi. 2018;21(10):1099-102 30370506.

8. Choi JK, Park YS, Jung DH, Son SY, Ahn SH, Park DJ, et al. Clinical relevance of the tumor location-modified Lauren Classification System of gastric cancer. J Gastric Cancer. 2015;15(3):183-90. https:/doi.org/10.5230/jgc.2015.15.3.183.

9. Selcukbiricik F, Tural D, Bilici A, Uzel EK, Ozguroglu M, Demirelli F, et al. Clinicopathological features and localization of gastric cancers and their effects on survival in Turkey. Asian Pac J Cancer Prev. 2013;14(1):553-6. https://doi.org/10.7314/apjcp.2013.14.1.553.

10. Pacelli F, Papa V, Caprino P, Sgadari A, Bossola M, Doglietto GB. Proximal compared with distal gastric cancer: multivariate analysis of prognostic factors. Am Surg. 2001;67(7):697-703 11450793.

11. Costa LB, Toneto MG, Moreira LF. Do proximal and distal gastric tumours behave differently? Arq Bras Cir Dig. 2016;29(4):232-5. https://doi.org/10. 1590/0102-6720201600040005.

12. Park JC, Lee YC, Kim JH, Kim YJ, Lee SK, Shin SK, et al. Clinicopathological features and prognostic factors of proximal gastric carcinoma in a population with high Helicobacter pylori prevalence: a single-center, largevolume study in Korea. Ann Surg Oncol. 2010;17(3):829-37. https://doi.org/ 10.1245/s10434-009-0785-x.

13. Moher D, Liberati A, Tetzlaff J, Altman DG, PRISMA Group. Preferred Reporting Items for Systematic Reviews and Meta-Analyses: the PRISMA statement. PLoS Med. 2009;6(7):e1000097. https://doi.org/10.1371/journal.pmed.1000097.

14. Shea BJ, Reeves BC, Wells G, Thuku M, Hamel C, Moran J, et al. AMSTAR 2: a critical appraisal tool for systematic reviews that include randomised or non-randomised studies of healthcare interventions, or both. BMJ. 2017;358: j4008. https://doi.org/10.1136/bmj.j4008.

15. Sakaguchi T, Watanabe A, Sawada H, Yamada Y, Tatsumi M, Fujimoto H, et al. Characteristics and clinical outcome of proximal-third gastric cancer. J Am Coll Surg. 1998;187(4):352-7. https://doi.org/10.1016/s10727515(98)00191-4. 
16. Piso P, Werner U, Lang H, Mirena P, Klempnauer J. Proximal versus distal gastric carcinoma--what are the differences? Ann Surg Oncol. 2000 Aug;7(7): 520-5. https://doi.org/10.1007/s10434-000-0520-0.

17. Huang Q, Shi J, Qi S, Gold JS, Chen J, Hongyan W, et al. Clinicopathological characterisation of small ( $2 \mathrm{~cm}$ or less) proximal and distal gastric carcinomas in a Chinese population. Pathology. 2015;47(6):526-32. https:// doi.org/10.1097/PAT.0000000000000276.

18. Zhan W, Cai S, He Y, Zhen Z, Peng J, Chen Z, et al. Prognostic comparison between proximal and distal gastric cancer and analysis of its cause. Chin J Gastrointestinal Surg. 2002;5(01):9-12.

19. Li C. Prognostic difference between proximal and distal gastric cancer and analysis of its causes. Guangxi Medical University; 2005.

20. Hong J, Zhang C, Yang N, Chen J, Chen H, Yang H. Prognostic comparison between proximal and distal gastric cancer and analysis of its causes. J Clin Res. 2005:22(10):1423-1424+1428.

21. Norouzinia M, Asadzadeh H, Shalmani HM, Al Dulaimi D, Zali MR. Clinical and histological indicators of proximal and distal gastric cancer in eight provinces of Iran. Asian Pac J Cancer Prev. 2012;13(11):5677-9. https://doi. org/10.7314/apjcp.2012.13.11.5677.

22. Strong VE. Progress in gastric cancer. Updates Surg. 2018;70(2):157-9. https://doi.org/10.1007/s13304-018-0543-3.

23. Howson CP, Hiyama T, Wynder EL. The decline in gastric cancer: epidemiology of an unplanned triumph. Epidemiol Rev. 1986;8:1-27. https:// doi.org/10.1093/oxfordjournals.epirev.a036288.

24. Devesa SS, Blot WJ, Fraumeni JF Jr. Changing patterns in the incidence of esophageal and gastric carcinoma in the United States. Cancer. 1998;83: 2049-53 PMID: 9827707.

25. Kuipers EJ. Review article: exploring the link between Helicobacter pylori and gastric cancer. Aliment Pharmacol Ther. 1999;13(Suppl 1):3-11. https:// doi.org/10.1046/j.1365-2036.1999.00002.x.

26. Shimatani T, Inoue M, Iwamoto K, Hyogo H, Yokozaki M, Saeki T, et al. Prevalence of Helicobacter pylori infection, endoscopic gastric findings and dyspeptic symptoms among a young Japanese population born in the 1970s. J Gastroenterol Hepatol. 2005;20(9):1352-7. https://doi.org/10.1111/j. 1440-1746.2005.03866.X.

27. Lee S-Y, Park H-S, Yu SK, Sung I-K, Jin C-J, Choe WH, et al. Decreasing prevalence of Helicobacter pylori infection: a 9-year observational study. Hepatogastroenterology. 2007;54(74):630-3 PMID: 17523338.

28. Kim JH, Kim HY, Kim NY, Kim SW, Kim JG, Kim JJ, et al. Seroepidemiological study of Helicobacter pylori infection in asymptomatic people in South Korea. J Gastroenterol Hepatol. 2001;16(9):969-75. https://doi.org/10.1046/j. 1440-1746.2001.02568.x.

29. Yonemura Y, Tsugawa K, Fonseca L, Fushida S, Matsumoto H, Ninomiya I, et al. Lymph node metastasis and surgical management of gastric cancer invading the esophagus. Hepatogastroenterology. 1995;42(1):37-42 PMID: 7782032.

30. Tajima Y, Nakanishi Y, Yoshino T, Kokawa A, Kusano M, Shimoda T. Clinicopathological study of early adenocarcinoma of the gastric cardia: comparison with early adenocarcinoma of the distal stomach and esophagus. Oncology. 2001;61(1):1-9. https://doi.org/10.1159/000055345.

31. Hosokawa Y, Kinoshita T, Konishi M, Takahashi S, Gotohda N, Kato Y, et al. Clinicopathological features and prognostic factors of adenocarcinoma of the esophagogastric junction according to Siewert classification: experiences at a single institution in Japan. Ann Surg Oncol. 2012 Feb;19(2): 677-83. https://doi.org/10.1245/s10434-011-1983-x.

32. Martin HM, Filipe MI, Morris RW, Lane DP, Silvestre F. p53 Expression and prognosis in gastric carcinoma. Int J Cancer. 1992;50:859-62. https://doi.org/ 10.1002/ijc.2910500604

33. Starzynska T, Markiewski M, Domagala W, Marlicz K, Mietkiewski J, Roberts SA, et al. The clinical significance of p53 accumulation in gastric carcinoma. Cancer. 1996;77(10):2005-12 doi: 10.1002/(SICI)1097-0142(19960515)77:10< 2005::AID-CNCR7>3.0.CO;2-P.

34. Mao W, Chen J. The difference of gastric cancer prognosis between Eastern country and Western country: what is and why is? Chin J Curr Adv Gen Surg. 2001;4(2):65-7.

35. He Y. The current situation and difference of surgical treatment of gastric cancer between eastern and Western countries. J Practical Oncol. 2008;23(2):93-6.

\section{Publisher's Note}

Springer Nature remains neutral with regard to jurisdictional claims in published maps and institutional affiliations.

Ready to submit your research? Choose BMC and benefit from:

- fast, convenient online submission

- thorough peer review by experienced researchers in your field

- rapid publication on acceptance

- support for research data, including large and complex data types

- gold Open Access which fosters wider collaboration and increased citations

- maximum visibility for your research: over $100 \mathrm{M}$ website views per year

At $\mathrm{BMC}$, research is always in progress.

Learn more biomedcentral.com/submissions 